\title{
Влияние сезонности на объем реализации услуг
}

\section{Логачева А.В., студентка, Санкт-Петербургский государственный экономический университет, 2. Санкт-Петербург E-mail: anna logacheva94@mail.ru}

Научный руководитель: к.с.н., доцент Печерица Е.В.

В настоящее время учет отклонений от среднегодовой нормы показателей нескольких месяцев в области гостеприимства всегда учитывается в следующих действиях:

- $\quad$ анализ процесса реализации услуг;

- $\quad$ выбор способа реализации услуг [2, с. 48].

Вместе с тем можно отметить, что в индустрии гостеприимства на структуру занятости трудовых ресурсов оказывают влияние следующие факторы:

- ограниченная возможность карьерного роста;

- $\quad$ малое количество высококвалифицированных работников;

- $\quad$ объем трудовой нагрузки, который изменяется в зависимости от сезона

Объем услуг, который можно реализовать в сезон зависит от следующих факторов:

- $\quad$ период отпуска;

- каникулы;

- $\quad$ время года.

Вместе с тем закономерность отклонений у показателей отдельных месяцев от среднегодовых показателей также должна учитываться, если в области гостеприимства проводится анализ планирования объемов предложенных услуг. В данных случаях и на практике сезонные колебания изучают при помощи статистики. Кроме того методики расчета индекса сезонности будут применяться при проведении уже экономического анализа.

При этом среди основных методик расчета можно выделить:

- $\quad$ расчет относительных чисел;

- расчет аналитического выравнивания;

- $\quad$ простые и средние расчеты

Как правило, для вычисления сезонной динамики, когда внутригодовое изменение объема реализованных услуг колеблется на протяжении определенного периода, в частности на протяжении года, применяется самый простой метод - простые и средние расчеты [1, с. 95].

Необходимо отметить, что индексы сезонности рассчитываются в несколько этапов:

1. Расчет для каждого месяца по данным за все время исследуемых периодов средних уровней показателей

Данный принцип поможет устранить случайные колебания месячных уровней по годам. И поэтому на начальном этапе применяются простые и средние расчеты, где на общее число единиц разделяется частное от деления суммы значений всех вариантов

2. Определение за весь период времени. 
Между тем разделение общей суммы исходных данных (общего объема явления за весь исследуемый период) на число месяцев в исследуемом периоде - это расчет по абсолютным данным об объеме явления сезонных колебаний.

Однако уже деление общей суммы исходных данных на общее число календарных дней в исследуемом периоде определяет уже расчет на основе среднесуточных уровней. Также во время сбыта гостиничных услуг иногда может выстроиться такая модель сезонности, которые в этой отрасли поможет оценить колебательные процессы. При этом и в самой организации постоянно меняется динамика и интенсивность, так как они подвержены влиянию условий сезонности [1, с. 104]. Как правило, движение определяется, такими фактами как:

- объем реализованных услуг;

- $\quad$ рост или спад производительности труда и показателей деятельности организации, что существенно влияет на прибыль в целом.

Кроме того, если есть возможность, любые случайные колебания следует исключать. Между тем нельзя путать случайные ошибки и случайные колебания. В связи с этим компоненты, которые очень неожиданно отражаются на исследуемом процессе - это случайные колебания. К примеру, объем спроса на отели горнолыжных территорий будет практически незаметен, если неожиданно наступит теплая зима.

Важно заметить, что среднемесячные, а может даже и среднеквартальные данные за определенный период времени в большинстве случаев применяются, чтобы сгладить случайные колебания. И поэтому данные да последние 3-5 лет берутся, чтобы получить более точную картину всего происходящего. А вот уже статистические приемы применяются для выявления и отображения сезонных колебаний. В связи с этим расчет индекса сезонности до сих пор является самым простым и точным способом выявления таких колебаний [2, с. 46].

Вместе с тем если обратиться к зарубежной и отечественной литературе, то здесь на данный момент выделяются следующие методы:

- метод переменной средней;

- метод постоянной средней;

- метод скользящей средней;

- $\quad$ метод нахождения взвешенных индексов сезонности.

В настоящее время для нахождения данных индексов используются указанные методы. При этом самым логичным и простым методом, чтобы определить величину колебательных процессов является метод постоянной средней. Данный метод еще применяется, когда отсутствует значительная тенденция убывания или роста. В таких случаях вокруг определенного на протяжении изучаемого периода постоянного уровня (несколько лет) колеблются все внутригодичные изменения.

А вот если тенденция развития (нисходящая или восходящая) просматривается очень ярко, то используется метод переменной средней [2, с. 56]. Как правило, теоретические уровни - это база сравнения. Кроме того эти теоретические уровни так как их расчет базируется на положениях метода наименьших квадратов рассматривается как «средняя ось кривой».

Необходимо отметить, что если сезонная динамика изучается по данным за специальный период, то за счет наличия общей тенденции их можно отграничить от изменений уровня, а с помощью нахождения взвешенных индексов сезонности они отделяются от случайных колебаний, которые могут изменить характер всего индекса сезонности. При этом через нахождение взвешенных средних могут быть усреднены 
индивидуальные индексы сезонности. Между тем квартальные или месячные уровни года - это баланс.

Вместе с тем сезонная линия тренда и эмпирические данные требуются, для того чтобы выявить тенденцию сезонной волны и закономерности сезонности. На данный момент метод скользящей средней - это самый простой способ, чтобы выявить сезонную линию тренда. Именно этот метод через расчет средней величины способен выявить и устранить общую тенденцию развития изучаемого явления [8].

В то же время, если рассматривать российский гостиничный рынок и сезонные колебания спроса на нем, то здесь в качестве основных методов выступают:

1. Метод переменной средней.

Как правило, данный метод применяют, если прослеживается четкая тенденция развития

2. Метод простой средней.

Указанный метод в случае убывания или отсутствия существенной тенденции роста во время рассматриваемого времени, помогает выявить саму сезонность [4, с. 50]

Важно заметить, что для оценки экономической эффективности компании в настоящее время применяется большое количество подходов и методов. При этом финансовая модель, которая является усовершенствованием методов бухгалтерского учета, является самой популярной и применяемой. Если рассматривать суть данной модели, то она на основе расчета внутренних показателей деятельности оценивает экономическую эффективность компании и ее отстранение от внешнего влияния. При этом увеличение прибыли, которое достигается благодаря снижению издержек - это основное проявление роста эффективности финансовой модели [4, с. 52].

Кроме того нельзя не отметить и группирование позиционирования по специальной характеристике. Между тем финансовая деятельность должна при своем совершенствовании учитывать:

- $\quad$ применение прогрессивных приемов труда;

- $\quad$ поиск и анализ внутрипроизводственных резервов;

- $\quad$ стимулирование производства в экономическом плане;

- $\quad$ планирование деятельности компании [5].

Вместе с тем управление прибылью в своем процессе зависит и от последствий, которые учитывают изменение информационного обеспечения, и от факторов, которые действуют на данный момент. При этом ключевая задача грамотного экономического управления заключается в изучении информационного обеспечения плановоуправленческих решений [6].

В связи с этим стабилизировать экономическое положение компаний и позволить им существовать в будущем можно, благодаря эффективному совершенствованию системы управления и грамотному использованию своего потенциала. Как правило, предприятия, которые возлагают все надежды лишь на меры государственной поддержки, очень часто не в силах выдержать конкуренции [7].

Таким образом, процесс стратегического и оперативного планирования, постоянного контроля и коррекции реализации плана повышения эффективности производства, как результата управления, можно назвать эффективностью производства [3, с. 36].

Между тем, если данную эффективность анализировать, то здесь выделяются определенные методы: 
1. Структурный (вертикальный) анализ, который выявляет воздействие позиций на весь результат и в виде относительных показателей бухгалтерской отчетности отражает баланс.

2. Временной (горизонтальный) анализ, обнаруживающий все изменения в бухгалтерской отчетности.

3. Трендовый анализ, который помогает прогнозировать полученные значения для деятельности фирмы в будущем.

4. Сравнительный анализ, который сравнивает показания как отделов внутри компании, так и с компаниями-конкурентами.

5. Анализ финансовых коэффициентов (относительных показателей), помогающий рассчитать числовые отношения разных форм отчетности, которые установят взаимосвязь между показателями.

6. Факторный анализ, который дает возможность с помощью детерминированных или стохастических приемов исследования изучить, как на результативный показатель влияют отдельные факторы.

Таким образом, в период сезонного спада спроса на услуги изучение эффективности деятельности компании, осуществляется с помощью комплексного анализа, где рассматриваются показатели:

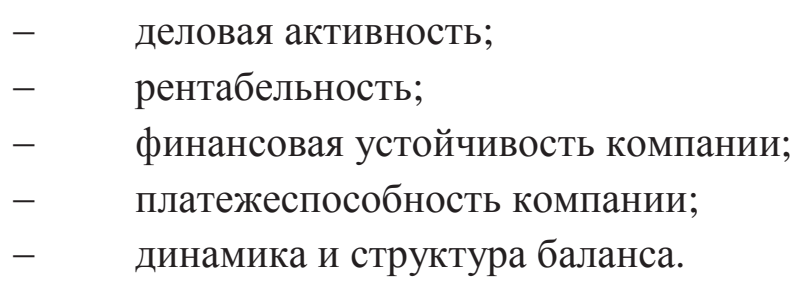

\section{Список литературы:}

1. Баумгартен Л.В. Управление качеством в туризме: практикум: учеб. пособие. - Москва, 2009.

2. Влодарчик Б., Стасяк А., Качмарек Я. Туристический продукт. - М.: Юнити, 2008.

3. Стратегия развития туризма в Российской Федерации на период до 2015 года. - М.: Федеральное агентство по туризму (Ростуризм), 2012.

4. Федеральный закон "Об обществах с ограниченной ответственностью" от 08.02.1998 N 14-Ф3 . - [Электронный ресурс] - http://www.consultant.ru/popular/ooo/ (Дата обращения 27.02.2017).

5. Печерица Е.В. Позиционирование предприятий индустрии гостеприимства в условиях конкуренции. монография / Е. В. Печерица; М-во образования и науки Российской Федерации, Федеральное агентство по образованию, Санкт-Петербургский гос. ун-т сервиса и экономики. Санкт-Петербург, 2010. 163 с.

6. Рубан Д.А. Инновационный менеджмент в туризме: направления и управленческие действия. Вестник УрФУ. Серия: Экономика и управление. 2015. Т. 14. № 1. С. 114-126.

7. Печерица Е.В., Шевченко М.И. Инновационные технологии в гостиничном бизнесе. монография / Санкт-Петербургский государственный университет сервиса и экономики. Санкт-Петербург, 2013. 135 с.

8. Печерица Е.В. Понятие сезонности в туристической индустрии. В сборнике: Актуальные проблемы развития индустрии гостеприимства. сборник трудов. Под редакцией О. Н. Кострюковой, О. А. Никитиной, Е. В. Печерица. 2016. С. 164-167. 